\title{
Correlation between parity and metabolic syndrome in Chinese women aged 40 years and older: the Reaction study
}

\author{
Qian Xie ${ }^{1 *}$, Haoran $X^{2}$ and Qin Wan ${ }^{3}$
}

\begin{abstract}
Aims: The purpose of the present study was to investigate the correlation between the number of live-birth pregnancies and metabolic syndrome (MetS) in Chinese women according to menstruation history.

Methods: Registry data for all pregnancies in a cohort of 6157 Chinese women aged 40 years or older were obtained and the number of live-birth pregnancies were enumerated. We defined MetS using five criteria: impaired insulin metabolism and glucose tolerance, obesity in the abdominal area, dyslipidemia, and hypertension. Multivariate logistic regression analysis was conducted to assess potential risk factors for MetS. Postmenopausal women with three or more of live-birth pregnancies had the highest prevalence of MetS $(P<0.05)$.

Results: Among the 6157 females aged 40 years or older in Luzhou city, 2143 (34.8\%) participants had incident MetS. The number of live-birth pregnancies was significantly correlated with age and fasting blood glucose (FBG) level $(P<0.05)$. The prevalence of MetS increased with the number of live-birth pregnancies $(P<0.01)$, and the frequency in postmenopausal women was significantly higher than that in premenopausal women $(P<0.001)$. In the binary logistic regression model, menopausal status [OR $=0.343(0.153-0.769), P<0.001]$ were significantly associated with an increased risk of MetS.

Conclusions: The number of live-birth pregnancies is correlated with an increased risk of MetS in Chinese women aged 40 years and over, especially in postmenopausal women. Greater attention should be paid to postmenopausal women who have had multiple live-birth pregnancies with a view to intervening early to prevent related diseases.
\end{abstract}

Keywords: Live-birth pregnancies, Metabolic syndrome, Menopause, Diabetes, Hypertension, Obesity

\section{Introduction}

Metabolic syndrome (MetS) is a multifaceted disease characterized by impaired insulin metabolism and glucose tolerance, obesity in the abdominal area, dyslipidemia, and hypertension [1]. According to statistics, approximately $20-25 \%$ of the population worldwide suffers from this syndrome [2]. The prevalence of MetS in the U.S. population has been estimated to be $25.0 \%$ [3],

\footnotetext{
* Correspondence: 994814082@qq.com

'Department of Gerontology, the people's Hospital of LeShan, LeShan 614000, China

Full list of author information is available at the end of the article
}

and a meta-analysis conducted in mainland China demonstrated a pooled frequency of $24.5 \%$ (19.25\% in males and $27.0 \%$ in females) [4]. The incidence of MetS continues to increase, causing serious economic burden to society, especially in developing countries. Reports have indicated a high prevalence of MetS in the Philippines (19.7\%) [5], Malaysia (27.5\%) [6], Nigeria (28.1\%) [7], India (28.2\%) [8], Brazil (29.6\%) [9], Iran (36.9\%) [10], and Turkey (44.0\%) [11]. MetS is considered to increase the risk of all-cause and cardiovascular disease (CVD) mortality, incident stroke, cancer, and sleep disorders [12-15]. A recent study showed that individuals with

(c) The Author(s). 2021 Open Access This article is licensed under a Creative Commons Attribution 4.0 International License, which permits use, sharing, adaptation, distribution and reproduction in any medium or format, as long as you give appropriate credit to the original author(s) and the source, provide a link to the Creative Commons licence, and indicate if changes were made. The images or other third party material in this article are included in the article's Creative Commons licence, unless indicated otherwise in a credit line to the material. If material is not included in the article's Creative Commons licence and your intended use is not permitted by statutory regulation or exceeds the permitted use, you will need to obtain permission directly from the copyright holder. To view a copy of this licence, visit http://creativecommons.org/licenses/by/4.0/ The Creative Commons Public Domain Dedication waiver (http://creativecommons.org/publicdomain/zero/1.0/) applies to the data made available in this article, unless otherwise stated in a credit line to the data. 
MetS have a 2-fold increased risk of developing CVD and a 5 -fold increased risk of developing type 2 diabetes as compared with individuals without MetS [16].

Although pregnancy is a limited process, its impact on a woman's physiological status is lengthy and marked; thus, middle-aged and elderly multiparous women are at a high risk of MetS. Pregnancy leads to significant metabolic changes, such as increased production of insulin; reduced insulin sensitivity; and increased fat mass, triglycerides, low-density lipoprotein cholesterol, and blood glucose $[17,18]$. Although these changes that occur during pregnancy are almost completely reversed following delivery, the lasting effects of the state of inflammation can result in an increased risk of hypertension and CVD in later life [19 20]. A Danish cohort study found that the highest risk of developing hypertension and CVD in premenopausal women is during their first live-birth pregnancy and after their fourth [21]. A follow-up study in the U.S. indicated that BMI in women aged $45-74$ is significantly positively correlated with the number of live-birth pregnancies [22]. A recent study showed that older multiparous women are more likely to develop impaired glucose regulation (IGR) and diabetes than their counterparts with fewer children. Moreover, it has been reported that the number of children is also associated with MetS and diabetes in men [23]. However, knowledge is lacking regarding the correlation between MetS and the number of live-birth pregnancies in Chinese women aged 40 years and over; thus, in the present study, we investigated this correlation, in addition to the association between menopause and MetS.

\section{Methods}

\section{Study population}

The cross-sectional study data were taken from REACTION [24], a longitudinal study investigating cancer risk in Chinese diabetics, which was performed between April and November 2011 by the Chinese Medical Association endocrine branch. In brief, the baseline data for 6157 females aged 40 years or older in Luzhou city were selected. Extensive training relative to the study questionnaire and outcome measures was received by the investigators prior to the beginning of the investigation. Each participant provided written informed consent relating to participation in this study. Following the ethical standards in Declaration of Helsinki, ethical approval of this study was obtained from the Research Ethics Committee, the Affiliated Hospital of Southwest Medical University. Inclusion criteria were: 1) permanent residents aged $\geq 40$ years; 2 ) gender: female; and 3 ) good compliance. Subjects were excluded according to the following parameters: pregnant women, lack of mobility, old age( $>85$-year-old), weakness, communication barriers, poor compliance, history of long-term chronic diseases, recent acute diseases, and women who had never given birth.

The National Cholesterol Education Program (NCEP ATP III) criteria [15] for MetS were used to classify subjects without previously known MetS when three of the following five components were present: 1) abdominal obesity: female waist circumference $\geq 85 \mathrm{~cm} ; 2$ ) increased blood glucose: fasting blood glucose $\geq 6.1 \mathrm{mmol} / \mathrm{L}$, blood glucose $\geq 7.8 \mathrm{mmol} / \mathrm{L} 2 \mathrm{~h}$ after a meal and/or diagnosed with diabetes, currently under anti-diabetic treatment; 3 ) hypertension: blood pressure $\geq 130 / 85 \mathrm{mmHg}$ and/or diagnosed with hypertension; 4) on an empty stomach HDL-C $<1.04$ tendency $/ \mathrm{L} ; 5)$ fasting triglycerides $(\mathrm{TG}) \geq$ $1.7 \mathrm{mmol} / \mathrm{L}$.

\section{Other measures}

During the baseline interview, all participants were asked about gender, age, family history of diabetes, degree of education, age at menopause, age at which their first child was born, alcohol consumption and smoking habits, and number of live-birth pregnancies (excluding other children: adopted, fostered, step). Smoking status was defined as current smoking and still smoking 1 year prior to baseline.

A physical examination was carried out, during which blood pressure was measured at the right brachial artery 3 times in a seated position, at 5-min intervals, using an automatic sphygmomanometer. Height and body weight were measured with the individual wearing light-weight clothes and no shoes, and body mass index (BMI) was subsequently calculated by dividing the weight $(\mathrm{kg})$ by the height $(\mathrm{m})^{2}$. Measurement of the waist circumference was performed at the midway level between the iliac crest and the costal margin.

Blood samples were taken following an 8-h overnight fast. All subjects underwent an OGTT ( $82.5 \mathrm{~g}$ glucose). The glucose oxidase test and colorimetric enzyme assays were employed to determine plasma levels of glucose, triglycerides (TG), hemoglobin A1c, high-density lipoprotein cholesterol (HDL-C), and low-density lipoprotein cholesterol (LDL-C). Informed consent was obtained from all subjects.

\section{Statistical analysis}

The database was established using the Epidata software. Continuous variables are expressed as the mean $\pm \mathrm{SD}$, and two-sided $P<0.05$ was considered statistically significant. Continuous variables were analyzed using oneway analysis of variance, If the difference was statistically significant, Bonferroni method was used for pairwise comparison. Categorical variables were analyzed via the X2 test. Logistic regression was used to evaluate the influence of factors related to the number of live-birth 
pregnancies on MetS. SPSS 19.0 was used for statistical analysis.

\section{Results}

A total of 6157 females aged 40 years and over were selected for the present study (average age, $58.7 \pm 10.1$ years). In China, women who have never given birth account for less than $1 \%$ of the total number of women over 40 and were therefore excluded. Women were grouped according to the number of live-birth pregnancies: women with 1 live birth, one (3754, 60.97\%); women with 2 live births, two $(1459,23.70 \%)$; women with 3 live births, three (603, 9.79\%); and women with 4 and more live births, four or more (341, 5.54\%). The characteristics of each group are shown in Table 1. The results indicate that the number of live-birth pregnancies $(P<0.01)$ and FBG $(P<0.01)$ increased with age. The family history of diabetes was significantly lower as the number of live-birth pregnancies increased $(P<0.05)$. Women with 1 live birth and 2 live births had a lower 2hPG, HbA1c, waist circumference, and SBP as compared with those in the other two groups $(P<0.05)$. TG, BMI and hip circumference in women with 1 live birth were significantly lower than those in the other groups $(P<0.05)$, and HDL-C in women with 1 live birth was significantly higher than that in the other groups $(P<$ $0.01)$. However, there was no significant difference in 2hPG, HbA1c, TC, TG, HDL-C, LDL-C, waist circumference, hip circumference, or SBP between women with
3 live births and 4 live births. The number of live-birth pregnancies did not cause a significant improvement in DBP (Table 1).

Among the 2143 (34.8\%) participants with incident MetS, there were 1017 (27.1\%) in women with 1 live birth, $618(42.4 \%)$ in women with 2 live births, 325 (53.9\%) in women with 3 live births, and 183 (53.7\%) in women with 4 and more live births. The prevalence of MetS increased significantly as the number of live-birth pregnancies increased $(P<0.01)$, with women with 4 and more live births having the highest prevalence of MetS $(P<0.05)$ (Table 2).

Table 3 presents the distribution of MetS morbidity under different menstruation situations. The prevalence of MetS in women over 40 years old was $34.8 \%$, of which premenopausal women accounted for $16.6 \%$ and postmenopausal women accounted for $39.2 \%$. The significant difference was found between pre- and postmenopausal women $(P<0.001)$. In the women with 1 live birth, 2 live births and 3 live births, the frequency of MetS was significantly higher in postmenopausal women than that in premenopausal women $(P<0.001)$. The prevalence of MetS in premenopausal women was significantly increased as the number of live-birth pregnancies increased $(P<0.05)$. Postmenopausal women showed an increasing trend in the prevalence of MetS as the number of live-birth pregnancies increased $(P<0.001)$, with women in women with 4 and more live births having the highest prevalence of MetS $(P<0.05)$ (Table 3$)$.

Table 1 Characteristics of the study participants according to the number of live-birth pregnancies

\begin{tabular}{|c|c|c|c|c|c|c|}
\hline \multicolumn{7}{|c|}{ The number of live-birth pregnancies (number) } \\
\hline Variable & $1(3754,60.97 \%)$ & $2(1459,23.70 \%)$ & $3(603,9.79 \%)$ & $\geq 4(341,5.54 \%)$ & $\mathrm{F}$ or $x^{2}$ & $P$ \\
\hline Age (years) & $53.8 \pm 7.9^{\wedge}$ & $60.3 \pm 9.0^{\Delta \square}$ & $67.7 \pm 7.1^{\triangle} \boldsymbol{\Delta}$ & $72.0 \pm 6.4^{\triangle} \Delta$ & 1028.094 & $<0.001$ \\
\hline FBG (mmol/L) & $5.73 \pm 1.44$ ৫י & $5.92 \pm 1.60^{\Delta \bullet}$ & $6.08 \pm 1.60^{\Delta}$ & $6.25 \pm 1.77^{\triangleleft} \boldsymbol{\Delta}$ & 24.524 & $<0.001$ \\
\hline $2 \mathrm{hPG}(\mathrm{mmol} / \mathrm{L})$ & $7.24(6.10,9.17) \boldsymbol{\Lambda}$ & $8.24(6.70,10.67)^{\Delta \square \cdot}$ & $8.90(7.29,12.37)^{\Delta} \boldsymbol{\Lambda}$ & $9.24(7.51,12.88)^{\Delta} \boldsymbol{\Lambda}$ & 80.341 & $<0.001$ \\
\hline $\mathrm{HbA1c}(\%)$ & $5.99 \pm 0.96$ & $6.20 \pm 1.04^{\Delta \square \bullet}$ & $6.34 \pm 1.08^{\Delta} \boldsymbol{\Lambda}$ & $6.44 \pm 1.29^{\wedge} \boldsymbol{\triangle}$ & 42.710 & $<0.001$ \\
\hline TC $(\mathrm{mmol} / \mathrm{L})$ & $4.68 \pm 1.14^{\square}$ & $4.73 \pm 1.20$ & $4.85 \pm 1.22^{\Delta}$ & $4.77 \pm 1.12$ & 4.313 & 0.005 \\
\hline $\mathrm{TG}(\mathrm{mmol} / \mathrm{L})$ & $1.25(0.89,1.80) \boldsymbol{\Lambda} \square$ & $1.36(0.96,2.01)^{\Delta}$ & $1.42(1.05,2.09)^{\Delta}$ & $1.37(0.97,1.94)^{\triangle}$ & 58.816 & $<0.001^{\mathrm{a}}$ \\
\hline $\mathrm{HDL}-\mathrm{C}(\mathrm{mmol} / \mathrm{L})$ & $1.31 \pm 0.35^{\mathbf{\Lambda}}$ & $1.26 \pm 0.34^{\Delta}$ & $1.27 \pm 0.33^{\Delta}$ & $1.26 \pm 0.32^{\Delta}$ & 10.831 & $<0.001$ \\
\hline LDL-C (mmol/L) & $2.61 \pm 0.82^{\square}$ & $2.65 \pm 0.86$ & $2.73 \pm 0.88^{\Delta}$ & $2.70 \pm 0.85$ & 4.688 & 0.003 \\
\hline BMI $\left(\mathrm{kg} / \mathrm{m}^{2}\right)$ & $23.5 \pm 3.2$ & $24.3 \pm 3.2^{\Delta}$ & $24.3 \pm 3.5^{\Delta}$ & $24.2 \pm 3.5^{\Delta}$ & 24.088 & $<0.001$ \\
\hline Waist circumference $(\mathrm{cm})$ & $80.0 \pm 9.8$ & $83.2 \pm 10.0^{\triangle \square}$ & $84.8 \pm 10.0^{\triangle} \boldsymbol{\Lambda}$ & $85.3 \pm 11.2^{\triangle} \boldsymbol{\Lambda}$ & 79.751 & $<0.001$ \\
\hline Hip circumference $(\mathrm{cm})$ & $92.7 \pm 9.2$ & $94.4 \pm 9.3^{\Delta}$ & $95.0 \pm 8.4^{\Delta}$ & $95.1 \pm 8.8^{\triangleleft}$ & 22.727 & $<0.001$ \\
\hline $\mathrm{SBP}(\mathrm{mmHg})$ & $120.0 \pm 18.5$ & $126.7 \pm 19.4^{\Delta \square \cdot}$ & $133.2 \pm 21.3^{\Delta} \boldsymbol{\Lambda}$ & $134.9 \pm 19.2^{\Delta \boldsymbol{\Lambda}}$ & 147.387 & $<0.001$ \\
\hline $\mathrm{DBP}(\mathrm{mmHg})$ & $75.3 \pm 10.4$ & $76.0 \pm 10.4$ & $75.5 \pm 11.1$ & $74.6 \pm 11.7$ & 2.272 & 0.078 \\
\hline Family history of diabetes (\%) & $23.8 \%$ & $14.3 \%$ & $11.7 \%$ & $7.5 \%$ & 113.133 & $<0.001^{\mathrm{b}}$ \\
\hline Age when first gave birth birth & $20.6 \pm 4.4$ & $20.3 \pm 4.8$ & $20.2 \pm 5.2$ & $21.6 \pm 6.7^{\triangle} \boldsymbol{\Delta}$ & 2.130 & 0.094 \\
\hline Menopausal status (Yes/No) & $2687 / 1067$ & $1256 / 203$ & $585 / 18$ & $339 / 2$ & 358.481 & $<0.001^{b}$ \\
\hline
\end{tabular}

Abbreviations: DBP, diastolic blood pressure; FBG, fasting blood glucose; 2hPG, postprandial blood glucose; SBP, systolic blood pressure, LDL-C, low-density lipoprotein cholesterol; HDL-C, high-density lipoprotein cholesterol

${ }^{\triangle} P<0.05$ as compared with group $1 ;{ }^{\Delta} P<0.05$ as compared with group $2 ;{ }^{\square} P<0.05$ as compared with group $3 ;{ }^{\bullet} P<0.05$ as compared with group 4 
Table 2 Comparison of the prevalence of MetS among the four groups

\begin{tabular}{|c|c|c|c|c|c|}
\hline Number of live-birth pregnancies & MetS & Total & Morbidity (\%) & $x^{2}$ & $P$ \\
\hline 1 & 1017 & 3754 & 27.1 & 229.962 & $<0.001$ \\
\hline 2 & 618 & 1459 & 42.4 & & \\
\hline 3 & 325 & 603 & 53.9 & & \\
\hline$\geq 4$ & 183 & 341 & 53.7 & & \\
\hline Total & 2143 & 6157 & 34.8 & & \\
\hline
\end{tabular}

In the binary logistic regression model, we found that FBG [OR $=1.629, P<0.05]$, 2hPG [OR $=1.394, P<0.001]$, BMI $[\mathrm{OR}=1.113, P=0.049]$, TG $[\mathrm{OR}=4.682, P<0.001]$, HDL-C $[\mathrm{OR}=0.009, P<0.001], \mathrm{SBP}[\mathrm{OR}=1.055, P<$ $0.001]$, waist circumference $[\mathrm{OR}=1.143, P<0.001]$, and menopausal status $[\mathrm{OR}=0.343, P<0.001]$ were significantly associated with an increased risk of MetS, whereas elevated age, HbA1c, TC, pregnancy number, DBP, hip circumference, and age at which the first child was born were not. The analysis results indicate that the number of livebirth pregnancies $[\mathrm{OR}=1.368, P=0.154]$ was only a suspect factor that did not reach statistical significance. Moreover, FBG, 2hPG, TG, HDL-C, menopausal status, SBP, and waist circumference were all independent risk factors for MetS following adjustment for other factors (Table 4).

\section{Discussion}

MetS is a serious public health concern resulting from a sedentary lifestyle and poor diet. The prevalence of MetS has been shown to be significantly higher in women than that in men. In the present study, we investigated the correlation between the number of live-birth pregnancies and MetS in women aged 40 years and over in Sichuan, China. It has previously been reported that the pooled incidence of MetS in China is 33.9\% (31.0\% in men and 36.8\% in women), indicating that approximately 454 million adults are affected [25]. At present, the pathogenesis of MetS remains unclear, and its occurrence is the result of a combination of factors including those of genetic and social environmental origin. One study found that MetS is linked to older age, lower educational level, and high levels of uric acid, alanine transaminase (ALT), gamma-glutamyl transferase $(\gamma-\mathrm{GT})$, and creatinine in a Taiwanese cohort [26]. Goeun et al. [27] demonstrated that among men and women aged 50-64 years, living without a spouse, having a low educational level, and reporting a low economic status were associated with MetS prevalence. In a crosssectional study of 1326 women, Goh et al. [28] observed that those with abdominal obesity are more likely to suffer from MetS, suggesting that waist circumference increases the risk of developing MetS. Moreover, pregnancy can lead to obesity due to the accumulation of body fat, reduction in physical activity, and increased calorie diet.

However, the notion that the number of live-birth pregnancies is an independent predictor of MetS remains controversial. In a cross-sectional study involving a total of 1251 elderly women (aged 60-95 years) [29], a strong association was observed between reproductive variables and a higher risk of MetS; women who had given birth a larger number of times had elevated ORs for MetS. When using the first tertile of the number of live-birth pregnancies as a reference, ORs for the second and third tertiles were 1.36 (95\% CI: 0.95-1.96) and 1.75 (95\% CI: 1.19-2.57) respectively, following adjustment for age, marital status, educational level, current smoking habit, current consumption of alcohol, $30 \mathrm{~min}$ of physical activity per day, BMI, and family history of CVD. A cross-sectional study of 4098 postmenopausal women performed using the Korean National Health and Nutrition Examination Survey found that the more times a woman gives birth, the higher the risk of MetS [30]. In contrast, another study found that increasing parity has no effect on insulin sensitivity or $\beta$-cell function [31]. A further study showed that multiple live-birth

Table 3 The distribution of MetS morbidity under different menstruation situations

\begin{tabular}{|c|c|c|c|c|c|c|c|c|}
\hline \multirow{2}{*}{$\begin{array}{l}\text { Number of } \\
\text { live-birth } \\
\text { pregnancies }\end{array}$} & \multicolumn{3}{|c|}{ Premenopausal } & \multicolumn{3}{|c|}{ Postmenopausal } & \multirow[t]{2}{*}{$x^{2}$} & \multirow[t]{2}{*}{$P$} \\
\hline & MetS & Total & Morbidity \% & MetS & Total & Morbidity \% & & \\
\hline 1 & 167 & 1067 & 15.7 & 846 & 2687 & 31.5 & 78.183 & $<0.001$ \\
\hline 2 & 41 & 203 & 24.3 & 497 & 1099 & 45.2 & 26.350 & $<0.001$ \\
\hline 3 & 5 & 20 & 25.0 & 320 & 583 & 54.9 & 4.142 & 0.042 \\
\hline$\geq 4$ & 2 & 2 & 100.0 & 181 & 339 & 53.4 & 0.862 & 0.353 \\
\hline Total & 215 & 1292 & 16.6 & 1844 & 4708 & 39.2 & 62.457 & $<0.001$ \\
\hline$x^{2}$ & 9.542 & & & 135.877 & & & - & - \\
\hline$P$ & 0.002 & & & $<0.001$ & & & - & - \\
\hline
\end{tabular}


Table 4 Multiple logistic regression analysis of risk factors for MetS

\begin{tabular}{lllllll}
\hline Variable & $\boldsymbol{B}$ & $\boldsymbol{S}$.E & Wald & $\boldsymbol{P}$ & $\mathbf{O R}$ & $\mathbf{9 5 \% C l}$ \\
\hline Number of live-birth pregnancies & 0.314 & 0.220 & 2.032 & 0.154 & 1.368 & $0.889 \sim 2.106$ \\
Age & 0.043 & 0.023 & 3.673 & 0.055 & 1.044 & $0.999 \sim 1.092$ \\
FBG & 0.464 & 0.150 & 9.574 & 0.002 & 1.629 & $1.468 \sim 1.843$ \\
2hPG & 0.332 & 0.053 & 40.001 & 0.000 & 1.394 & $1.258 \sim 1.545$ \\
BMI & 0.107 & 0.054 & 3.867 & 0.049 & 1.113 & $1.000 \sim 1.237$ \\
TG & 1.544 & 0.314 & 24.122 & 0.000 & 4.682 & $2.529 \sim 8.869$ \\
HDL-C & -4.700 & 0.941 & 24.940 & 0.000 & 0.009 & $0.001 \sim 0.058$ \\
Menopausal status & -1.070 & 0.412 & 6.752 & 0.009 & 0.343 & $0.153 \sim 0.769$ \\
SBP & 0.054 & 0.009 & 33.265 & 0.000 & 1.055 & $1.036 \sim 1.075$ \\
Waist circumference & 0.133 & 0.022 & 35.599 & 0.000 & 1.143 & $1.094 \sim 1.194$
\end{tabular}

OR was computed using the binary logistic regression model. All covariables were included simultaneously in the model. Elevated age, HbA1C, TC, number of livebirth pregnancies, DBP, hip circumference, and age at which the first child was born were not significantly associated with an increased risk of diabetes and were therefore not included in the final model

$\mathrm{B}$, unstandardized regression coefficients; SE, standard error; OR, odds radio

pregnancies are linked with the development of diabetes in elderly women, which appeared to be confounded and/or mediated by weight fluctuations and sociodemographic parameters. Higher parity does not appear to pose an ongoing risk of developing diabetes in older women [32]. Cohen et al. [33] observed that the rate of MetS among a national sample of women increased as the number of live-birth pregnancies increased; however, the strength of these correlations reduced following additional adjustment for BMI, which indicated that weight or changes thereof could be a vital mediator of the effect of the number of live-birth pregnancies on MetS risk. This is in accordance with the results of our study, in which the rate of participants with incident MetS was $34.8 \%$. We found that groups 3 and 4 had an approximate 2-fold increased prevalence of MetS as compared with that in women with 1 live birth. The prevalence of MetS significantly increased as the number of live-birth pregnancies increased; however, it was not an independent risk factor for MetS following adjustment for age, FBG, 2hPG, BMI, TG, HDL-C, SBP, waist circumference, menopausal status, bA1c, TC, pregnancy number, DBP, hip circumference, and age. Increased risk of MetS could obscure the influencing power of parity.

In the present study, we also found that the prevalence of MetS in premenopausal women was $16.6 \%$ and that in postmenopausal women was $39.2 \%$, which are similar results to those of a meta-analysis showing that the global prevalence rate of MetS in postmenopausal women is $37.17 \%$, much higher than that in premenopausal women. A cross-sectional study [34] conducted in a sample of 640 women aged 40-65 years old showed that the prevalence of MetS varies with menopausal status: $45.7 \%$ in premenopausal women and $57.5 \%$ in postmenopausal women. A retrospective study in 958 women aged 40-65 years old conducted in southern Brazil found that the incidence of MetS in postmenopausal women (22.2\%) was much higher than that in premenopausal women $(8.4 \%)(R R=2.75)$, suggesting that menopausal status affects the incidence of MetS in women [35]. These data are consistent with those from a Korean study showing an OR of 2.93 for the incidence of MetS in post- as compared with premenopausal women after controlling for age, BMI, and other confounders [25]. Another study showed that the longer a woman has been postmenopausal, the higher the occurrence of MetS, with the OR increasing from 1.40 to 1.58 in a time-dependent manner [29]. These observations are similar to those in our study showing that postmenopausal status $[\mathrm{OR}=0.343(0.153-0.769), P<0.001]$ was an independent risk factor for MetS.

The present study shows that the incidence of MetS in postmenopausal women was significantly higher than that in premenopausal women $(P<0.001)$ when the number of live-birth pregnancies was less than 3 . Postmenopausal women showed an increasing trend in the prevalence of MetS as the number of live-birth pregnancies increased $(P<0.001)$. Moreover, postmenopausal women with increasing numbers of live-birth pregnancies had an approximate 2-fold increased prevalence of MetS as compared with that of premenopausal women. Postmenopausal women who had had three or more live-birth pregnancies had the highest prevalence of MetS $(P<0.05)$. Previous studies have indicated that both hormone therapy and individualized lifestyle intervention can reduce the incidence of MetS in postmenopausal women [36]. Greater attention should be paid to postmenopausal women who have had a greater number of live-birth pregnancies with a view to preventing related chronic diseases.

The specific mechanism underlying the effect of the number of live-birth pregnancies and menopausal status 
on MetS remains unknown but may be related to the following three aspects. Firstly, pregnancy is a temporary, non-physiological condition for a menstrual woman such as insulin resistance, dyslipidemia, fat accumulation, inflammation, and weight gainbut most of these alterations revert to the nonpregnant state after delivery, some changes could persist and even accumulate across successive pregnancies [32]. Previous research has reported waist girth increases with each birth, while bodyweight increased only after the first birth which was consistent with our research [37]. Secondly, most mothers spend the majority of their time caring for children and change in lifestyle risk factors; therefore, reduced physical exercise can lead to obesity, further insulin resistance, and enhanced glucocorticoid activity [38]. Thirdly, the levels of sex hormones change in menopausal women and the estrogen level begins to decline. Since the protective effect of estrogen is weakened, disorders related to blood glucose and lipid metabolism can easily develop, which increase the risk of CVD, diabetes, and other metabolic disorders [39].

This study has limitations. The study only looks at chinese women. No information was available about the pregnancy state, such as gestational weight gain, postpartum weight retention or pregnancy complications, in the current study.

In summary, the number of live-birth pregnancies was associated with a higher risk of MetS. Postmenopausal women who have had three or more live-birth pregnancies had the highest prevalence of MetS; therefore, attention should be paid to these individuals with a view to preventing related chronic diseases.

\section{Conclusions}

The number of live-birth pregnancies is correlated with an increased risk of MetS in Chinese women aged 40 years and over, especially in postmenopausal women. Greater attention should be paid to postmenopausal women who have had multiple live-birth pregnancies with a view to intervening early to prevent related diseases.

\section{Abbreviations \\ MetS: metabolic syndrome; CVD: cardiovascular disease; IGR: impaired glucose regulation; TG: triglycerides; HDL-C: high-density lipoprotein cholesterol; LDL-C: low-density lipoprotein cholesterol; FBG: fasting blood glucose; 2hPG: postprandial blood glucose; DBP: diastolic blood pressure; SBP: systolic blood pressure; BMI: body mass index}

\section{Acknowledgements}

We are thankful for all the participants of this study.

\section{Authors' contributions}

Qian Xie supervised the project. Qian Xie and Qin Wan secured funding. Qian Xie and Qin Wan designed and conceived the study. Haoran XU collected samples. Qian Xie and Haoran Xu performed data analysis and drafted the manuscript.Qian Xie and Qin Wan interpreted the results jointly.
All listed authors reviewed and approved the final manuscript, figures, and supplementary materials.

\section{Funding}

This work is supported by the grants 2016YFC0901200 and 2016YFC0901205 from the Ministry of Science and Technology. The funders had no role in

study design, data collection and analysis, decision to publish, or preparation of the manuscript.

\section{Availability of data and materials}

The datasets used and/or analysed during the current study are available from the corresponding author on reasonable request.

\section{Declarations}

\section{Ethics approval and consent to participate}

Ethical approval of this study was obtained from the Research Ethics Committee, the Affiliated Hospital of Southwest Medical University. Fully informed, written consent was obtained from the participants.

\section{Consent for publication}

Not applicable.

\section{Competing interests}

The authors declare that they have no competing interests.

\section{Author details}

'Department of Gerontology, the people's Hospital of LeShan, LeShan 614000, China. ${ }^{2}$ The first clinical institute, ZunYi Medical University, ZunYi 5630066 , China. ${ }^{3}$ Department of Endocrinology, the Affiliated Hospital of Southwest Medical University, Luzhou 641400, China.

Received: 8 July 2021 Accepted: 15 November 2021

Published online: 24 November 2021

\section{References}

1. Azizi F, Hadaegh F, Khalili D, Esteghamati A, Hosseinpanah F, Delavari A, et al. Appropriate definition of metabolic syndrome among Iranian adults: report of the Iranian National Committee of obesity. Arch Iran Med. 2010; 13(5):426-8.

2. Vidigal Fde C, Ribeiro AQ, Babio N, et al. Prevalence of metabolic syndrome and pre-metabolic syndrome in health professionals: LATINMETS Brazil study. Diabetol Metab Syndr. 2015;7(1):1758-5996. https://doi.org/10.1186/ s13098-015-0003-X.

3. Vahid S, Sahar G, Mohammadtaghi S, et al. The frequency of metabolic syndrome among female patients admitted in psychiatry ward. Med J Mashhad Univ Med Sci. 2012;54:230-7.

4. Li R, Li W, Lun Z, et al. Prevalence of metabolic syndrome in mainland China: a meta-analysis of published studies. BMC Public Health. 2016 Apr 01; 16(1):296. https://doi.org/10.1186/s12889-016-2870-y.

5. Sy RG, Llanes EJ, Reganit PF, et al. Socio-demographic factors and the prevalence of metabolic syndrome among filipinos from the LIFECARE cohort. J Atheroscler Thromb. 2014;21(1):S9-17. https://doi.org/10.5551/ja t.21_Sup.1-S9.

6. Rampal S, Mahadeva S, Guallar E, Bulgiba A, Mohamed R, Rahmat R, et al. Ethnic differences in the prevalence of metabolic syndrome: results from a multi-ethnic population-based survey in Malaysia. PLoS One. 2012;7(9): e46365. https://doi.org/10.1371/journal.pone.0046365.

7. Oguoma VM, Nwose EU, Richards RS. Prevalence of cardio-metabolic syndrome in Nigeria: a systematic review. Public Health. 2015;129(5):413-23. https://doi.org/10.1016/j.puhe.2015.01.017.

8. Nag T, Ghosh A. Prevalence of metabolic syndrome in rural elderly of Asian Indian origin. Am J Hum Biol. 2015;27(5):724-7. https://doi.org/10.1002/a jhb.22697.

9. de Carvalho VF, Bressan J, Babio N, et al. Prevalence of metabolic syndrome in Brazilian adults: a systematic review. BMC Public Health. 2013;13(1):1198. https://doi.org/10.1186/1471-2458-13-1198.

10. Amirkalali B, Fakhrzadeh $H$, Sharifi F, et al. Prevalence of Metabolic Syndrome and Its Components in the Iranian Adult Population: A Systematic Review and Meta-Analysis. Iran Red Crescent Med J. 2015;17(12). 
11. Gundogan K, Bayram F, Gedik V, Kaya A, Karaman A, Demir Ö, et al. Metabolic syndrome prevalence according to ATP III and IDF criteria and related factors in Turkish adults. Arch Med Sci. 2013;9(2):243-53. https://doi. org/10.5114/aoms.2013.34560.

12. Benjamin EJ, Muntner P, Alonso A, et al. Heart disease and stroke Statistics2019 update: a report from the American heart association. Circulation. 2019;139:e56-66.

13. Martínez-Hernández A, Córdova EJ, Rosillo-Salazar O, et al. Association of HMOX1 and NQO1 Polymorphisms with Metabolic Syndrome Components. PLoS One. 2015;10(5).

14. Rochlani Y, Pothineni NV, Mehta JL. Metabolic syndrome: does it differ between women and men? Cardiovasc Drugs Ther. 2015;29(4):329-38. https://doi.org/10.1007/s10557-015-6593-6

15. Pearson-Stuttard J, Zhou B, Kontis V, Bentham J, Gunter MJ, Ezzati M. Worldwide burden of cancer attributable to diabetes and high body-mass index: a comparative risk assessment. Lancet Diabetes Endocrinol. 2018;6(6): e6-15. https://doi.org/10.1016/S2213-8587(18)30150-5.

16. Grundy SM. Does a diagnosis of metabolic syndrome have value in clinical practice? Am J Clin Nutr. 2006;83(6):1248-51. https://doi.org/10.1093/ajcn/ 83.6.1248.

17. Dahlgren J. Pregnancy and insulin resistance. Metab Syndr Relat Disord. 4(2): 149-52.

18. Lain KY, Catalano PM. Metabolic changes in pregnancy. Clin Obstet Gynecol. 50(4):938-48.

19. Gilmore LA, Klempel-Donchenko M, Redman LM. Pregnancy as a window to future health: excessive gestational weight gain and obesity. Semin Perinatol. 2015;39(4):296-303. https://doi.org/10.1053/j.semperi.2015.05.009.

20. Gongora MC, Wenger NK. Cardiovascular complications of pregnancy. Int J Mol Sci. 2015;16(10):23905-28. https://doi.org/10.3390/ijms161023905.

21. Chen SX, Rasmussen KM, Finkelstein J,et al. Maternal reproductive history and premenopausal risk of hypertension and cardiovascular disease: a Danish cohort study. BMJ Open.2019 $1104 ; 9(11)$ :e030702.

22. Ness RB, Harris T, Cobb J, Flegal KM, Kelsey JL, Balanger A, et al. Number of pregnancies and the subsequent risk of cardiovascular disease. N Engl J Med. 1993;328(21):1528-33. https://doi.org/10.1056/NEJM199305273282104.

23. Weng HH, Bastian LA, Taylor DH Jr, et al. Number of children associated with obesity in middle-aged women and men: results from the health and retirement study. J Womens Health (Larchmt). 2004;13(1):85-91.

24. Ning G, Reaction Study Group. Risk evaluation of cAncers in Chinese diabetic individuals:a LONgitudinal (REACTION) study. J Diabetes. 2012;4(2): 172-3. https://doi.org/10.1111/j.1753-0407.2012.00182.x.

25. Cho GJ, Lee JH, Park HT, Shin JH, Hong SC, Kim T, et al. Postmenopausal status according to years since menopause as an independent risk factor for the metabolic syndrome. Menopause. 2008;15(3):524-9. https://doi.org/1 0.1097/gme.0b013e3181559860.

26. Tsao YC, Li WC, Yeh WC,et al. The Association between Metabolic Syndrome and Related Factors among the Community-Dwelling Indigenous Population in Taiwan. Int J Environ Res Public Health.2020 1202 ;17(23).

27. Chung G, Jung HS, Kim HJ. Sociodemographic and health characteristics associated with metabolic syndrome in men and women aged $\geq 50$ years. Metab Syndr Relat Disord. 2020 Nov;12(3):159-66. https://doi.org/10.1089/ met.2020.0051.

28. Goh VHH, Hart WG. Excess fat in the abdomen but not general obesity is associated with poorer metabolic and cardiovascular health in premenopausal and postmenopausal Asian women. Maturitas. 2018 Jan;107: 33-8. https://doi.org/10.1016/j.maturitas.2017.10.002.

29. Liu M, He Y, Jiang B, Wu L, Wang J, Yang S, et al. Association between reproductive variables and metabolic syndrome in chinese community elderly women. Arch Gerontol Geriatr. 2016;63:78-84. https://doi.org/10.101 6/j.archger.2015.11.003.

30. Lee Y, Lee HN, Kim SJ, Koo J, Lee KE, Shin JE. Higher parity and risk of metabolic syndrome in Korean postmenopausal women: Korea National Health and nutrition examination survey 2010-2012. J Obstet Gynaecol Res. 2018 Nov;44(11):2045-52. https://doi.org/10.1111/jog.13766.

31. Iversen DS, Støy J, Kampmann U, Voss TS, Madsen LR, Møller N, et al. Parity and type 2 diabetes mellitus: a study of insulin resistance and $\beta$-cell function in women with multiple pregnancies. BMJ Open Diabetes Res Care. 2016;4(1):e000237. https://doi.org/10.1136/bmjdrc-2016-000237.

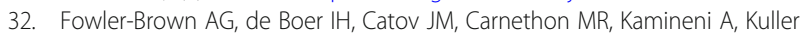
$\mathrm{LH}$, et al. Parity and the association with diabetes in older women. Diabetes Care. 2010 Aug;33(8):1778-82. https://doi.org/10.2337/dc10-00153(8).
33. Cohen A, Pieper CF, Brown AJ, et al. Number of children and risk of metabolic syndrome in women. J Womens Health (Larchmt). 2006;15(6): 763-73.

34. Rodrigues AD, Theodoro H, Mendes KG, Paniz VM, de Lorenzi D, Anselmo Olinto MT. Factors associated with metabolic syndrome in climacteric women of southern Brazil. Climacteric. 2013 Feb;16(1):96-103. https://doi. org/10.3109/13697137.2012.659099.

35. Marchi R, Dell'Agnolo CM, Lopes TCR, et al. Prevalence of metabolic syndrome in pre- and postmenopausal women. Arch Endocrinol Metab. 2017;61(2):160-6. https://doi.org/10.1590/2359-3997000000253.

36. Ruan XY, Yan D, Zhang JL, et al. Interventions on metabolic syndrome in postmenopausal women. Journal of Capital Medical University. 2013;34: 04,519-24.

37. Chandalia M, Lin P, Seenivasan T, Livingston EH, Snell PG, Grundy SM, et al. Insulin resistance and body fat distribution in south Asian men compared to Caucasian men. PLoS One. 2007;2(8):e812. https://doi.org/10.1371/journal. pone.0000812.

38. Manson JE, Rimm EB, Colditz GA, Stampfer MJ, Willett WC, Arky RA, et al. Parity and incidence of non-insulin- dependent diabetes mellitus. Am J Med. 1992 Jul;93(1):13-8. https://doi.org/10.1016/0002-9343(92)90674-Z.

39. Lovre D, Lindsey SH, Mauvais-Jarvis F. Effect of menopausal hormone therapy on components of the metabolic syndrome. Ther Adv Cardiovasc Dis. 2016

\section{Publisher's Note}

Springer Nature remains neutral with regard to jurisdictional claims in published maps and institutional affiliations.
Ready to submit your research? Choose BMC and benefit from:

- fast, convenient online submission

- thorough peer review by experienced researchers in your field

- rapid publication on acceptance

- support for research data, including large and complex data types

- gold Open Access which fosters wider collaboration and increased citations

- maximum visibility for your research: over $100 \mathrm{M}$ website views per year

At BMC, research is always in progress.

Learn more biomedcentral.com/submissions 